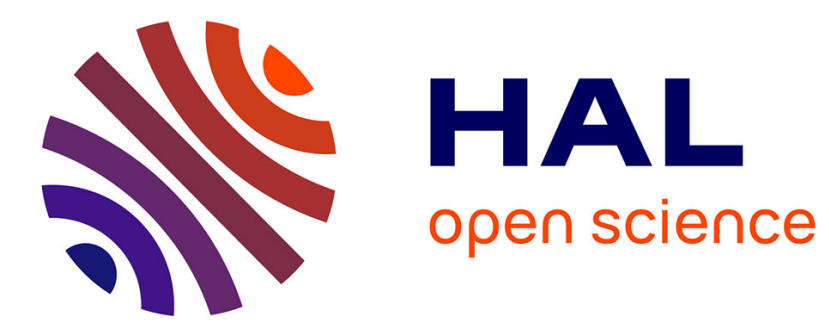

\title{
Ion extraction applications of bilayer-structured hybrid silicas
}

\author{
R. Besnard, R. Winkler, Guilhem Arrachart, J. Cambedouzou, S \\ Pellet-Rostaing
}

\section{- To cite this version:}

R. Besnard, R. Winkler, Guilhem Arrachart, J. Cambedouzou, S Pellet-Rostaing. Ion extraction applications of bilayer-structured hybrid silicas. Materials Chemistry Frontiers, 2018, 2 (5), pp.10311039. 10.1039/c8qm00022k . hal-02062506

\section{HAL Id: hal-02062506 https://hal.science/hal-02062506}

Submitted on 26 Oct 2021

HAL is a multi-disciplinary open access archive for the deposit and dissemination of scientific research documents, whether they are published or not. The documents may come from teaching and research institutions in France or abroad, or from public or private research centers.
L'archive ouverte pluridisciplinaire HAL, est destinée au dépôt et à la diffusion de documents scientifiques de niveau recherche, publiés ou non, émanant des établissements d'enseignement et de recherche français ou étrangers, des laboratoires publics ou privés. 


\title{
Ion extraction applications of bilayer-structured hybrid silicas
}

\author{
R. Besnard, R. Winkler, G. Arrachart, * J. Cambedouzou and S. Pellet-Rostaing * \\ ICSM, CEA, CNRS, ENSCM, Univ Montpellier, Bagnols sur Cèze Cedex, France. \\ E-mail: guilhem.arrachart@cea.fr; stephane.pellet-rostaing@cea.fr
}

The self-assembly behaviour of amino-undecyl-triethoxysilane, which can be considered as an amphiphilic organosilane, has been used for the preparation of nanostructured materials. Due to the possibilities offered by this approach, lamellar hybrid materials bearing amine groups can be achieved. In this study, the reactive amino groups at the surface of the hybrid silica were modified for introducing ligands. For this purpose, various glycolamic acid groups have been introduced at the interface between two bilayers on the hybrid material obtained after condensation of silylated amines. The availability of the amino groups and the efficiency of the chemical immobilization of amic acid ligands onto the materials were followed by FTIR, NMR and TGA analysis, and the structural modifications induced by grafting were evaluated by SAXS experiments. The resulting materials exhibit a large number of amic acid groups. The adsorption capacities for rare earth elements were also investigated.

\section{Introduction}

There is increasing interest in the development of new solid phase extraction materials based on organosilica. Silica-based organic-inorganic hybrids are attractive materials due to their versatility, which originates from the combination of their inorganic silica network properties and their organic constituents. ${ }^{1}$

Organosilica and mainly mesoporous organosilica sorbents have been actively investigated with success for the removal of

several inorganic species as heavy metal ions, ${ }^{2}$ toxic oxyanions, ${ }^{3}$ lanthanide/actinides, ${ }^{4,5}$ radionuclides ${ }^{6}$ or organic pollutants. ${ }^{7,8}$ For these applications, there are three major strategies for the synthesis of organosilica sorbents. ${ }^{9}$ The first strategy involves the chemical grafting of specific ligands on the surface ofmesoporous silica. An alternative synthesis procedure consists of a "one-pot" approach, in which themesoporous silica is formed and functionalized by the simultaneous co-condensation of tetraethoxysilane (TEOS) with an organosiloxane precursor in the presence of structure-directing agents. Higher organic loading can be achieved using bridging organic groups of the type $\left(\mathrm{R}^{\prime} \mathrm{O}\right)_{3} \mathrm{Si}-\mathrm{R}-\mathrm{Si}\left(O \mathrm{R}^{\prime}\right)_{3}$ as single-source organosilica precursors through the synthesis of periodic mesoporous organosilicas (PMOs), in which the organic bridges are incorporated in the threedimensional network structure of the silica matrix. ${ }^{10,11}$

Depending on the selected approaches, drawbacks ${ }^{12,13}$ can be problematic for solid phase extraction applications as follows: low functionalization and inhomogeneous distribution of the organic group ${ }^{12,14}$ lead to a significant part of functional groups being non-accessible, and the mesoscopic ordering formation can be disturbed.

In this context, aiming to overcome these drawbacks and improve the amount of available functional groups, a different approach has been explored to generate organosilicas using organosilane surfactant precursors. ${ }^{15-17}$ This "all-in-one" or "selftemplating" approach allows both dense functionalization and accessibility of the functionalities of the silica by taking advantage of the self-assembling and condensable properties of organosilane surfactant precursors. ${ }^{17}$ Different structural types of supramolecular materials could be obtained depending on the specific arrangement of the organosilane and on the amount of silica involved during the synthesis without the addition of more external surfactant. ${ }^{15}$ For example, various multi-layered organosilicate have been synthesized by a self-assembly process leading to hybrid materials with high adsorption capacity for transition metal cations. ${ }^{18,19}$

Recently, we took advantage of this approach using a simple amine (amino-undecyl-triethoxysilane). Organicinorganic hybrid materials with high amine content or aminooxy groups were obtained either with a lamellar or hexagonal periodicity from the self-assembly properties of this precursor under specific conditions. ${ }^{20-25}$ 
A primary amino group is one of the most attractive surface functionalities owing to its use as a ligand for various metal ions. ${ }^{3,26}$ We demonstrated the accessibility of the functional amine groups in materials prepared from a "all-in-one" approach through the performance of the materials engaged in the solid phase extraction of platinum or palladium salts, which are able to form strong complex bonds with amino functions. ${ }^{27}$

Solid phase extraction may require a high concentration and availability of functional groups. Taking into account such requirements, the preparation of silica materials bearing a high number of available amines represents a considerable challenge. Indeed, amino functions are useful for further post-synthesis functionalization, allowing various functionalities to be introduced by chemical modifications such as alkylation ${ }^{3,28}$ or the formation of amides $^{5,29,30}$ and imines. ${ }^{30,31}$

In this context, we first studied the availability of amines in amine-bearing silica lamellar materials and their postsynthesis functionalization for the introduction of selective ligands aimed at rare earth extraction. Inspired by the works of Ogata et al., ${ }^{32,33}$ we focused on opening ring reactions of anhydride succinic (S), glutaric (G) and diglycolic (D) leading to their respective amic acids (see Fig. 1).

The adsorption properties of amino functionalized materials was first compared to that of their analogous aminooxy functionalized materials. The discrepancies in extraction behaviours are discussed. The amine availability in regard to postfunctional groups is calculated from the grafting ratio obtained by FTIR, NMR and TGA analyses. The structural modifications induced by grafting were evaluated by SAXS experiments. Then, the ability of the materials to extract metal ions was also studied by comparing the extraction behaviour in nitric media between d group elements, silver and rare earths elements (REEs).

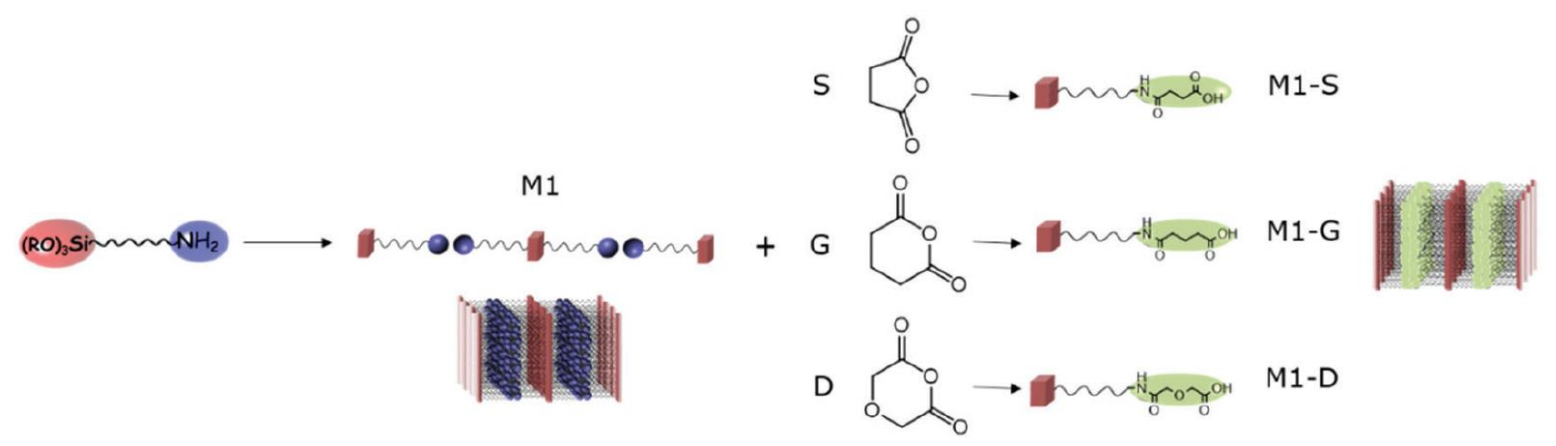

Fig. 1 Schematic representation of opening ring reaction of anhydride by lamellar amino functionalized silica, leading to lamellar amic functionalized silica M1-S, M1-G and M1-D.

\section{Results and discussion}

After the sol-gel process, thanks to the self-assembly behaviour of amino-undecyl-triethoxysilane, which can be considered as an amphiphilic organosilane, the preparation of lamellar hybrid material bearing easily available amine groups can be achieved. $\mathrm{CO}_{2}$ can be used as assembly agent leading to the formation of material $\mathrm{M} 1$ as bis-silylated-alkylammonium carbamate dimers arranged in a lamellar structure. ${ }^{23,27}$ The elimination of $\mathrm{CO}_{2}$ by heating allows obtaining materials with free amino groups in which the well-defined lamellar structure is maintained.

The possibility of the post-functionalisation of the reactive amino groups at the surface of the hybrid silica was studied through opening ring reactions of anhydride succinic (S), glutaric (G) and diglycolic (D) resulting in the nanostructured M1-S, M1-G, and M1-D.

\section{Post-grafting}

FTIR and NMR were used to investigate the grafting to provide evidence of the opening ring on the amino functions. Additionally, TGA and an elemental analysis were used together to quantify the grafting. The FTIR spectra (Fig. 2) of the materials exhibited the characteristic bands at around 2920 and $2850 \mathrm{~cm}^{-}$ ${ }^{1}$ corresponding to the $v_{\text {as }}(\mathrm{CH})$ and $v_{s}(\mathrm{CH})$ modes, respectively, of the alkyl chains. 

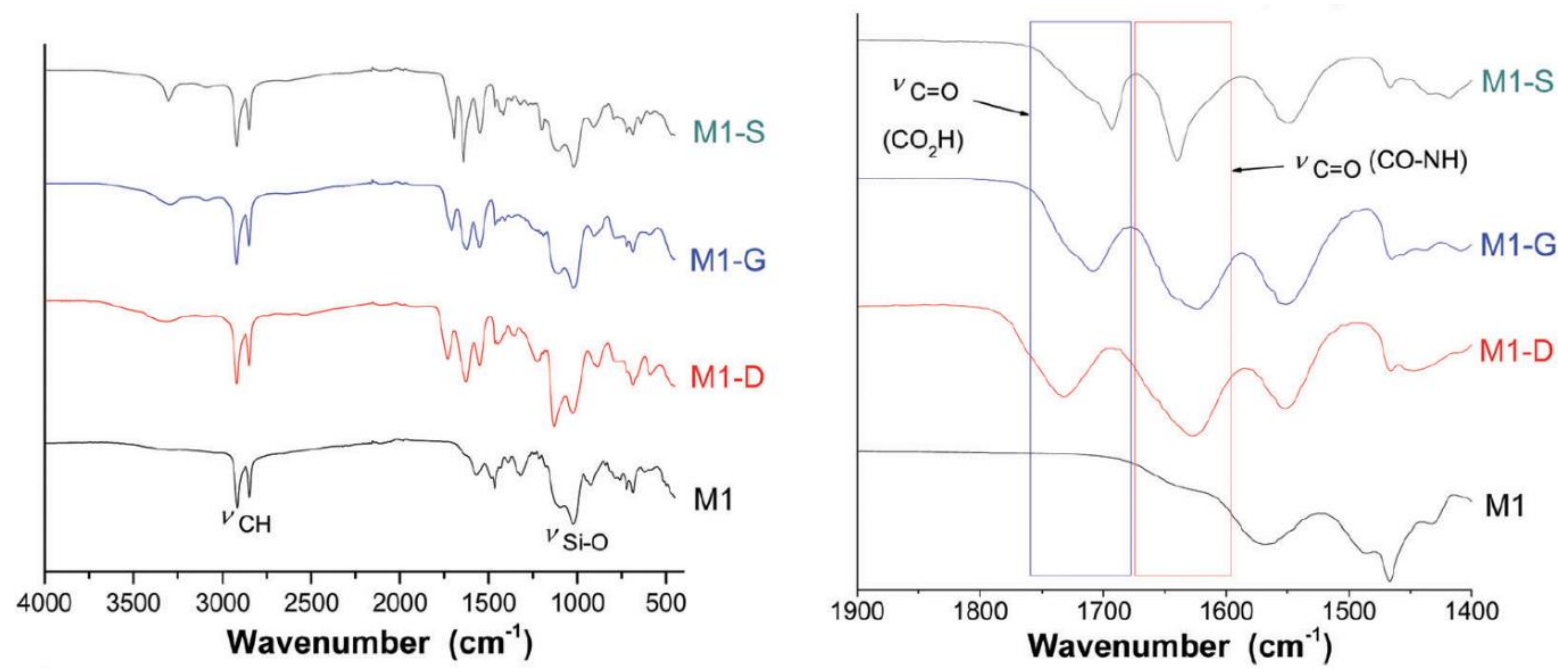

Fig. 2 FTIR spectra of M1, M1-S, M1-G and M1-D.

The intensity of these bands, comparatively to those corresponding to the silica matrix with Si-O-Si framework vibration ( $V_{\text {as }}(\mathrm{Si}-\mathrm{O})$ ) between 985 and $1160 \mathrm{~cm}^{-1}$, is representative of the high density of organic parts in the hybrid materials.

Fig. 2 shows a specific region included between 1450 and $1850 \mathrm{~cm}^{-1}$ of the FTIR spectra of the materials M1, M1S, M1-G, and M1-D. The M1 spectrum does not exhibit any intense band in the region included between 1450 and $1850 \mathrm{~cm}^{-1}$, and grafted materials spectra present three broad bands located at 1550, 1630 and $1700 \mathrm{~cm}^{-1}$. The bands at 1550 and $1630 \mathrm{~cm}^{-1}$ are usually attributed to the $\mathrm{N}-\mathrm{H}$ bending mode and the $\mathrm{C}=\mathrm{O}$ stretching mode of secondary amides, respectively. ${ }^{34}$ The band at $1700 \mathrm{~cm}^{-1}$ is known to be associated with the stretching mode of $\mathrm{C}=\mathrm{O}$ bound of a carboxylic acid. Notably, no band characterizing the carbonyl signal of the anhydride precursors was observed at $1800 \mathrm{~cm}^{-1}$, indicating that no residual trapped precursors are present in the material.

The solid-state ${ }^{13} \mathrm{C}$ NMR leads to the same conclusion. Fig. 3 shows the ${ }^{13} \mathrm{C}$ NMR spectrum of the M1-S material signals corresponding to the carbons of the different carbonyl groups previously mentioned. The carbon of the carboxylic acid is observed at 174 ppm, and the carbon of the amide is observed at $169 \mathrm{ppm}$.

The solid state NMR spectrum of M1 also presents a resonance signal located at $159 \mathrm{ppm}$, which is attributed to the carbamate carbonyl carbon, confirming the presence of ammonium carbamate salt as already observed in the literature. ${ }^{21}$

a)

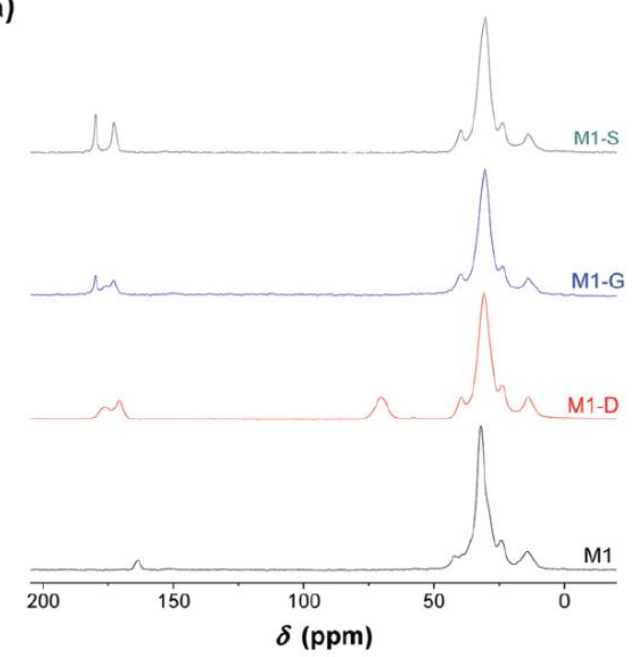

b)

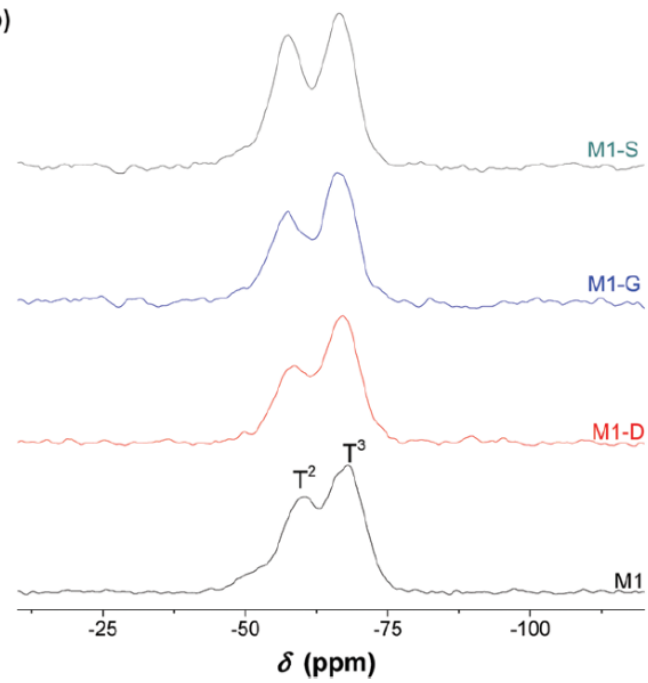

Fig. 3 (a) ${ }^{13} \mathrm{C}$ and (b) ${ }^{29} \mathrm{Si}$ solid-state NMR spectra of the bulk silica hybrid material (M1, M1-D, M1-G, M1-S). 
The solid-state ${ }^{29} \mathrm{Si}$ CPMAS NMR spectra exhibits $\mathrm{T}^{2}(-55 \mathrm{ppm})$ and $\mathrm{T}^{3}(-65 \mathrm{ppm})$ silicate centres with the condensation level estimated at around 85\%, which indicates that approximately five out of six silanol units in the material are condensed (see Table S1, ESI). ${ }^{35,36}$ The materials consist of highly condensed siloxane networks with organic fragments covalently bonded to the silica network. This suggestion was supported by the solidstate ${ }^{13} \mathrm{C}$ NMR spectra with the absence of signals attributable to residual ethoxy groups.

Spectroscopic measurements allow us to confirm the ring opening of the different precursors on the amine from the M1 material. Although information from these data seems to show that the grafting was complete, a quantitative analysis is required to provide solid evidence.

For this purpose, a thermogravimetric analysis was performed on materials from $30{ }^{\circ} \mathrm{C}$ to $1000{ }^{\circ} \mathrm{C}$ under air flow. The resulting weight losses for $\mathrm{M} 1$ and $\mathrm{M} 1-\mathrm{S}$ are shown in Fig. 4. The thermal profile of M1-G and M1-D are similar to that of M1-S (see Fig. S1, ESI). The results for the $\mathrm{M} 1$ material show a $\mathrm{CO}_{2}$ and water release of approximately $10.5 \mathrm{wt} \%$ between $70^{\circ} \mathrm{C}$ and $120^{\circ} \mathrm{C}$. The $\mathrm{CO}_{2}$ is initially used as the assembly agent leading to the formation of material M1 as bis-silylatedalkylammonium carbamate dimers arranged in a lamellar structure. ${ }^{23,27}$ This departure is no longer observed in the case of the M1-S material, reflecting the full substitution of the $\mathrm{CO}_{2}$ during the post-grafting step. This finding confirms that the amic acid groups have been introduced onto the M1 material.
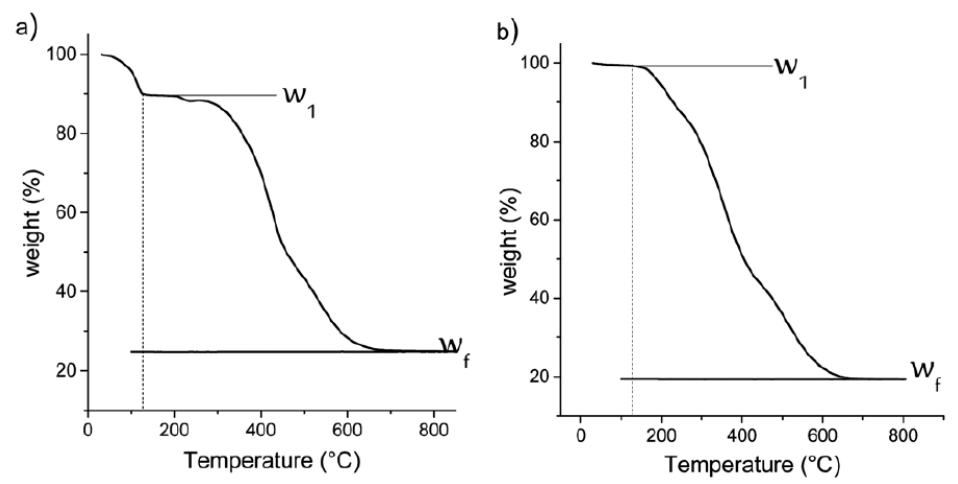

Fig. 4 Thermogravimetric analysis of (a) M1 and (b) M1-S.

In addition, the decrease of the residual weight $w_{\mathrm{f}}$ at the end of the analysis from 24.7 wt\% to $19.2 \mathrm{wt} \%$, respectively, for the M1 and M1-S materials involves a higher organic content into the initial material. The residual masses after calcination $w_{\mathrm{f}}$ can be considered as that of pure silica. Completely condensed silica presents a molar mass of $60 \mathrm{~g} \mathrm{~mol}^{-1}$. Considering that each silicon atom of the silica originates from condensed amino precursors or functionalized precursors of $x \mathrm{O}_{n} \mathrm{Si}\left(\mathrm{CH}_{2}\right)_{11} \mathrm{NH}_{2}-y \mathrm{OnSi}\left(\mathrm{CH}_{2}\right)_{11} \mathrm{NH}-\mathrm{R} z \mathrm{H}_{2} \mathrm{O}$, (where $\mathrm{n}$ is the number of oxygen molecules bounded on silicon, and $\mathrm{R}$ is the grafted moieties), the average molar mass $\mathrm{Mt}$ of the precursor can be deduced with eqn (1):

$\mathrm{Mt}=\frac{\mathrm{M}_{\mathrm{SiO} 2}}{w_{\mathrm{f}}}$

Additionally,

$\mathrm{Mt}=x \mathrm{M}_{\mathrm{M} 1}+y \mathrm{M}_{\mathrm{M} 1-\mathrm{x}}+z \mathrm{M}_{\mathrm{H} 2 \mathrm{O}}$

where $\mathrm{M}_{\mathrm{H} 2 \mathrm{O}}$ is the molar mass of water, $\mathrm{M}_{\mathrm{M} 1}$ is the molar mass of $\mathrm{M} 1$ at $125^{\circ} \mathrm{C}$, and $\mathrm{M}_{\mathrm{M} 1-\mathrm{x}}$ of its grafted analogous M1-X (with X=S, G, D).

Assuming that at $125^{\circ} \mathrm{C}$ the silica matrix is also completely condensed and dried, the fraction w1 corresponding to the fraction at $125^{\circ} \mathrm{C}$ corresponds to the material of formula $x \mathrm{O}_{1.5} \mathrm{Si}\left(\mathrm{CH}_{2}\right)_{11} \mathrm{NH}_{2}-y \mathrm{O}_{5} \mathrm{Si}\left(\mathrm{CH}_{2}\right)_{11} \mathrm{NH}-\mathrm{R}$ of average molar mass $\mathrm{Mt}^{*}$. 
Additionally,

$\mathrm{Mt}^{*}=x \mathrm{M}_{\mathrm{M} 1}+y \mathrm{Mt}_{\max } *$

where $\mathrm{Mt}_{\max } *$ is the molar mass expected for completely grafted and dried materials.

The conversion yield $y$ is obtained by resolving eqn (5):

$$
\left\{\begin{array}{l}
y=w_{1} \frac{\mathrm{Mt}^{*}-\mathrm{M}_{\mathrm{M} 1}}{\mathrm{Mt}_{\max }{ }^{*}-\mathrm{M}_{\mathrm{M} 1}} \\
x+y=1
\end{array}\right.
$$

Table 1 shows the picked and calculated data from the thermal analysis of the materials.

Completely condensed silica is considered, and the calculated values and grafting yields are minimized. Therefore, as suggested by spectroscopic analysis, the thermal analysis demonstrates a quantitative grafting by ring opening reaction on the functionalized amino@silica. In addition, the elemental analysis on the materials leads to the same conclusion (see Table S2, ESI).

Analyses allow for verification that a ring opening occurred in the quantitative yields. The introduction of such functional groups involves all the amine of the initial M1 material available from the reactional media. The availability of the amino groups located at the interfaces of bilayers in such material has been highlighted with the immobilization of platinoid salt complexes in the interlayer space. ${ }^{27}$ The chemical modification of the amino groups is therefore expected to involve structural modifications of the resulting grafted materials.

Table 1 Weight fractions $\left(w_{\mathrm{f}}, w_{1}\right)$, average dry $\left(\mathrm{Mt}^{*}\right)$, maximum dehydrated $\left(\mathrm{Mt}_{\max }{ }^{*}\right)$ molecular weight and conversion rates (y) for M1, M1-S, M1-G and M1-D.

\begin{tabular}{lccccc}
\hline & $\boldsymbol{w}_{\mathbf{f}}(\boldsymbol{\%})$ & $\boldsymbol{w}_{\mathbf{1}}(\mathbf{\%})$ & $\mathbf{M t}^{*}\left(\mathbf{g ~ m o l}^{-\mathbf{1}}\right)$ & $\mathbf{M t}_{\mathbf{m a x}}{ }^{*}\left(\mathbf{g ~ m o l}^{\mathbf{1}}\right)$ & $\boldsymbol{y}(\%)$ \\
\hline M1 & 24.7 & 89.7 & 218 & 222 & - \\
\hline M1-S & 19.2 & 99.8 & 312 & 322 & 90 \\
\hline M1-G & 18.5 & 99.3 & 322 & 336 & 88 \\
\hline M1-D & 17.6 & 98.3 & 335 & 338 & 98 \\
\hline
\end{tabular}

\section{Structural effects}

The amino functions are located at the interfaces of the bilayers built during the self-assembly of the aminoundecyltriethoxysilane precursor. The stacking of these bilayers corresponds to a lamellar structure highlighted in the SAXS profile of the material by structure peaks, for which the $q_{n} / q_{1}$ ratio is an integer $n$. Fig. 5 shows the SAXS profile of M1 and M1-S, and that of M1-G and M1-D are available in Fig. S2 (see ESI). We have identified the Bragg peaks originating from the lamellar structure. For the M1-S sample, five Bragg peaks denoted as $\mathrm{q}_{\mathrm{ns}}$ are clearly observed at scattering vectors of $1.6,3.3,4.8,6.4$ and $8.1 \mathrm{~nm}^{-1}$, corresponding to the five successive orders for a lamellar phase of parameter $3.9 \mathrm{~nm}$.

In the case of $\mathrm{M} 1$, only 3 peaks are resolved, corresponding to the first, second and fourth diffraction order of a lamellar phase of lattice parameter of $3.4 \mathrm{~nm}$. To determine the consistency of the initial lamellar structure, SAXS measurements were performed on each material. All of the results reveal that the lamellar structure is preserved after grafting. However, the lattice parameter characterizing the distance between bilayers is larger than that of M1. The SAXS profile of M1-S is presented in Fig. 5 to illustrate the phenomenon; those of M1-G and M1-D are available in Fig. S2 (ESI).

Indeed, all the peaks are shifted towards weaker angles. For instance, we note that q2 peak shifts from $3.7 \mathrm{~nm}^{-1}$ for $\mathrm{M} 1$ to $3.3 \mathrm{~nm}^{-1}$. 


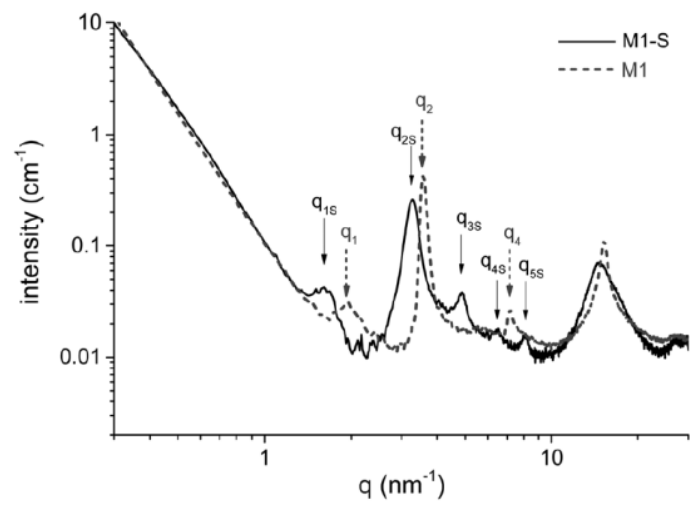

Fig. 5 SAXS profiles of M1 and M1-S.

From the $\mathrm{q}_{2}$ peak position, we calculated the swelling of the structure due to the chemical grafting. The interlayer distance $\Delta d$ calculated from the $\mathrm{q}_{2}$ peak position, and the expected lengths of the grafted functions $D_{f}$ are summarized in Table 2.

As previously demonstrated by thermal analysis, the $\mathrm{CO}_{2}$ constituting the carbamic acid of $\mathrm{M} 1$ has been eliminated during the grafting. Considering that the size of the carbamate groups is negligible and that they are all substituted by grafted functions, the expected swelling gap would be close to $2 \mathrm{D}_{\mathrm{f}}$.

However, the interlayer distances are close to $D_{f}$ for all of the grafted materials. These results suggest either a tilted lamellar structure or a bilayer structure where functional end chains are interpenetrated. The latest interpretation would likely be governed by hydrogen bounds between amides and acid groups.

We showed that the amino functions located at the bilayer interfaces were available for chemical modification. In addition, the functionalization has been completely performed for all the ring precursors without drastically damaging the initial lamellar structure. The ring opening reaction of cyclic anhydrides is thus an efficient way to functionalize amines from hybrid-structured silica. This reaction leads to multifunctional chemical patterns tunable by the nature of the grafted groups. Thus, we obtained amides coupled with terminal carboxylic acids bridged by two or three methylenes for M1-S and M1-G materials and a dimethylether for M1-D.

Table 2 Interlayer distance $\Delta d(n m)$ calculated from the $q 2$ peak position and the length $D_{f}(n m)$ of grafted groups for materials M1-S, M1-G and M1-D.

\begin{tabular}{lcc}
\hline & $\Delta \mathbf{d}(\mathbf{n m})$ & $\mathrm{D}_{\mathrm{f}}$ \\
\hline M1-S & 4 & 5 \\
\hline M1-G & 4 & 6.3 \\
\hline M1-D & 4 & 6.0 \\
\hline
\end{tabular}

\section{Extraction tests}

Extraction properties of M1 and M2 materials. Primary amino and oxyamino groups are one of the most attractive surface functionalities owing to their use as ligands for various metal ions. $3,24,27$

In addition, the grafted ligands contain chemical moieties also known to have affinities with specific metal ions. Indeed, if carboxylic acids can complex a large range of metal ions, ${ }^{4,37}$ amides $^{38,39}$ and amic acid ${ }^{40,41}$ seem peculiarly relevant as far as selective rare earth ion extraction is concerned.

Thus, we explore the extraction properties of materials in regard to the separation of $\mathrm{Y}^{3+}, \mathrm{Nd}^{3+}, \mathrm{Eu}^{3+}$ and $\mathrm{Dy}^{3+}$ representing the rare earth elements group. Usually, rare earth elements coming from ores of natural or urban origin are accompanied with iron and other $\mathrm{d}$-block elements. Therefore, iron, copper and cobalt have been added to the simulated leach. Aiming at completing the study, silver has been considered as a monovalent cation. 
The main aim of this study was to evaluate the affinities and the apparent selectivity of prepared materials in regard to these eight ions contained in different nitric acid solutions. The concentration in each ion was fixed at $0.1 \mathrm{mmol} \mathrm{L}^{-1}$. The mass of adsorbent material was $20 \mathrm{mg}$ for M1 and M2 and $25 \mathrm{mg}$ for the grafted material in order to obtain a ratio between ligands $(\mathrm{L})$ and metal ions $(\mathrm{M}) \mathrm{L} / \mathrm{M}$ close to 10 . Note that from $\mathrm{pH}=3$, iron ions precipitate and are eliminated from the solution before ICP-OES analysis. Therefore, the results for iron are not available for solutions containing $0.0001 \mathrm{M}$ of nitric acid. First, we evaluate the extraction capacity of M1 in different acidic condition. To determine the pKa effects on the extraction phenomena, the results are compared to those of $\mathrm{M} 2$, which is the analogous lamellarmaterial functionalized by an oxyamine. ${ }^{23}$

Fig. 6 a exhibits the extraction results of $M 1$ for different nitric acid concentrations. We note that M1 extracts few elements in the two higher acidic concentration values.

Only silver is significantly extracted, reaching $7 \%$ from the initial amount of this element for nitric acid concentration of $0.01 \mathrm{M}$, while at lower acid concentration $(\mathrm{pH}=4)$, copper and silver are quantitatively extracted (93\% and 97\%, respectively) and heavy rare earths, albeit in lower proportion.

In comparison, in the higher acidic conditions, M2 appears to behave as M1 since no significant extraction was observed (Fig. 6a and b). However, while at $0.01 \mathrm{M} \mathrm{HNO}_{3}$, the extraction properties of $\mathrm{M} 1$ are low, those of $\mathrm{M} 2$ exhibit affinities specifically for both elements coming from block 11 of the periodic table, since only silver and copper are quantitatively extracted at $80 \%$ and $60 \%$, respectively (Fig. 6b). For lower acid concentration $(0.0001$ $\mathrm{M})$, the extraction of silver and copper was complete, but M2 also extracts $60 \%$ of cobalt ions and $50 \%$ of all of rare earth ions $\left(\mathrm{Y}^{3+}, \mathrm{Nd}^{3+}, \mathrm{Eu}^{3+}\right.$ and $\left.\mathrm{Dy}^{3+}\right)$.

The use of silica-supported aliphatic amines reported by Soliman ${ }^{42}$ illustrated that the use of nitrogen donor atoms was an effective means of removing metals such as copper(II) ions.

The extraction properties of $M 1$ and $M 2$ seem to exhibit a similar behaviour to a certain extent, but the behaviours shifted with the $\mathrm{pH}$ of the aqueous media. The amino functions of $\mathrm{M} 1$ are initially under ammonium carbamate form, while oxyamino functions of M2 are supposed to be free. Moreover, the pKa of M1 amines is estimated to 10.6 against 5 for M2 oxyamines.

a)

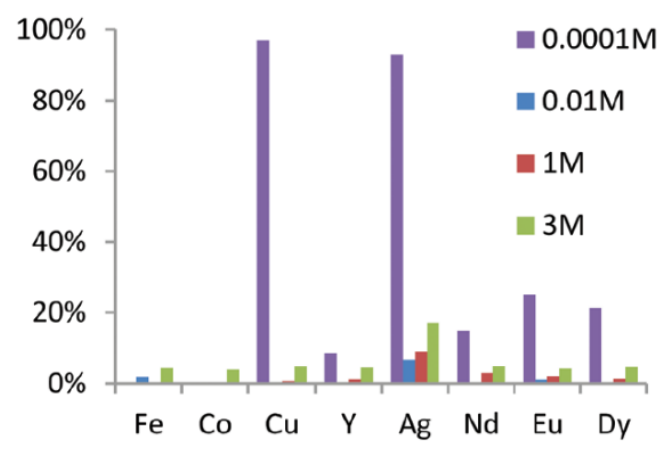

b)

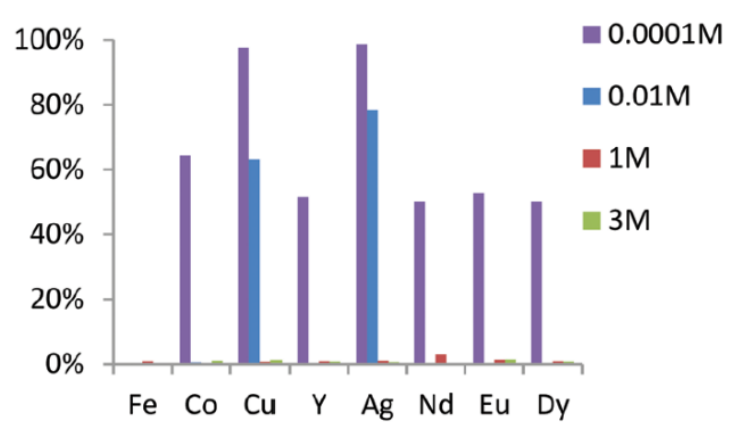

Fig. 6 Acidity dependence of metal ion percent adsorption for adsorbents (a) M1 and (b) M2 in nitric acid solution with a concentration in each ion fixed at $0.1 \mathrm{mM}$.

Two hypotheses can be expressed to explain these behaviour discrepancies between M1 and M2.

First, the ammonium carbamate, which hinders the bilayer interface constituting M1 material, is too stable in this thermal condition to allow extraction from solution. Second, in this acidic condition ( $\mathrm{pH}=2)$, amino and oxyamino functions are both mostly protonated under ammonium and oxyammonium form respectively for $\mathrm{M} 1$ and M2. However, the discrepancy between pKa values involves different equilibrium constants between the formation of ligand-metal species (non-protonated ligands) and non-chelating species (protonated ligands). Equilibrium promoting the formation of ligand-metal species would be observed for $\mathrm{M} 2$ at higher $\mathrm{pH}$. Owing to the same shifted extraction behaviour, the second hypothesis is supported.

Notably, at a $\mathrm{pH}$ value of 2, the calculated silver ion separation factor of $\mathrm{M} 2$ with respect to iron, and rare earth ions are included from 200 to 750, involving a higher selectivity. 
We have previously demonstrated the accessibility of amine from carbamate interfaces between bilayers in regard to platinoid anionic salt ${ }^{27}$ and the possibility of chemical modifications.

As previously shown by Alauzun et al. ${ }^{21}$ the availability of this function is also extended to cations in the ethanolic solution.

Here, we demonstrate that amino functions from carbamate interfaces are also accessible in nitric aqueous media in a selective way. Owing to the shifted similar extraction behaviour, this selectivity towards copper and silver ions seems to be governed by the pKa of terminal functions and thus by the $\mathrm{pH}$ of the solution.

\section{Extraction properties of grafted materials.}

The evaluation of the extraction properties of M1-S, M1-G and M1-D are compared in order to study the influence of the different extractant systems. The effects of bridge size between amides and terminal carboxylic acids will be illustrated by comparing M1-S and M1-G.

The effects of bridge nature will be exhibited by comparingM1-G and M1-D.

The extraction values for a nitric acid concentration of $0.01 \mathrm{M}$ of these three materials are shown in Fig. 7. M1-S and M1-G have the same affinities in regard to metal ions. Indeed, both extracts have exclusively iron ions in the same proportion, namely, $75 \%$ of the initial quantity and, to a lesser extent, silver ions (6-8\%). The increase by one carbon atom of the bridge between amide and carboxylic acid is not a dominant parameter to change the extraction properties. This result suggests that the extraction site of iron ion is not located between the abovementioned functions. While in M1-S and M1-G materials the bridges are composed of a methylene group, those of M1-D are ether groups. The M1-D material extracts iron ions in the same proportion, confirming the hypothesis that extraction sites of iron ions are not between the amide and carboxylic acid but rather on the carboxylic acid site, as suggested by the spectroscopic analysis of Ogata et al. ${ }^{33} \mathrm{M} 1-\mathrm{D}$ has also significant affinities in regard to all the REEs. Indeed, the extraction of yttrium ions reaches $72 \%$.

Among the heavy rare earths, the extraction yields increase with the atomic number (Fig. 7). This result has been already observed by Ogata et al. in hydrochloric acid aqueous media. ${ }^{32,33}$

An interesting point in order to selectively extract the rare earth element is to first perform the extraction of the aqueous feed solution using M1-S or M1-G to remove the iron and then perform the extraction of the REEs thanks to the material M1-D.

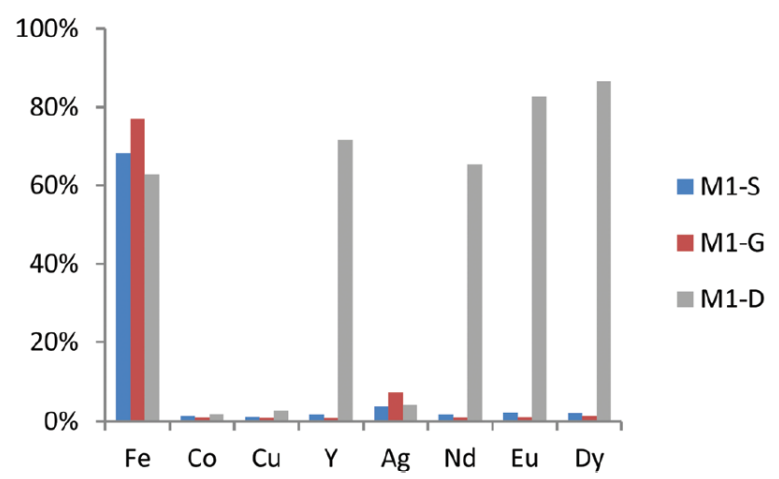

Fig. 7 Metal ion percent adsorption for M1-S, M1-G and M1-D from a $0.01 \mathrm{M}$ nitric acid solution with a concentration in each ion fixed at $0.1 \mathrm{mM}$.

Extraction experiments with a nitric acid concentration of $1 \mathrm{M}$ have been performed and reveal negligible extraction of all the elements in the leach, suggesting that quantitative backextraction is possible. Aiming at recovering the extracted rare earth ions from M1-D, we rinsed the material with a nitric acid aqueous solution at $3 \mathrm{M}$ for $24 \mathrm{~h}$ at $25^{\circ} \mathrm{C}$. The reported results in Fig. 8 reveal recovery yields of the extracted elements greater than $86 \%$, which could be considered quantitative.

To determine the maximum adsorption capacity of M1-D material in regard to dysprosium ions, we performed an extraction test in nitric acid solution $(0.1 \mathrm{mM})$ with an L/M ratio of 0.5 . 


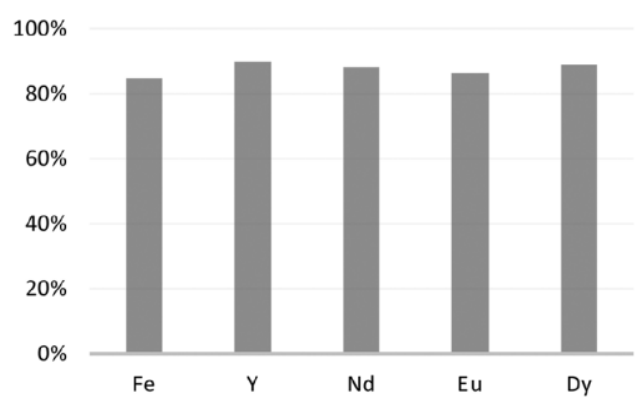

Fig. 8 Metal ion percent recovery after rinsing the adsorbent M1-D with nitric acid aqueous solution at $3 \mathrm{M}$ for $24 \mathrm{~h}$ at $25^{\circ} \mathrm{C}$.

In light of a structural investigation of the grafted materials, the presumed interpenetrated bilayers structure could have limited the extraction or back-extraction. However, the maximum adsorption capacity of dysprosium ions for M1-D materials was measured at $0.4 \mathrm{mmol} \mathrm{g}^{-1}\left(65 \mathrm{mg} \mathrm{g}^{-1}\right)$ involving an $\mathrm{L} / \mathrm{M}$ ratio of 7.2. Such ratio involves complete availability and accessibility of organic functions to allow trapping ions.

Few results involving amic acid loaded onto inorganic supports have been published in regards to adsorption of cations. The introduction of diglycol amic group on silica gel has been proposed by Ogata et al. with adsorption capacity Q E $20 \mathrm{mg} \mathrm{g}^{-1}$ for Dy. However, experiments have been realized at $\mathrm{pH}=1$ under hydrochloric acid. ${ }^{32}$ Similarly, adsorption capacity of about $8 \mathrm{mg} \mathrm{g}^{-1}$ with respect to Lu from $\mathrm{HNO} 3$ at $\mathrm{pH} 4$ has been reported but using mesoporous sorbents functionalized by phthaloyl diamide. ${ }^{43}$ Zheng et al. reported a $Q$ value between

50 and $80 \mathrm{mg} \mathrm{g}^{-1}$ with respect to $\mathrm{Gd}$ for an adsorbent based on modified mesoporous silica support with maleic anhydride under comparable conditions $\left(\mathrm{HNO}_{3} \mathrm{pH}=4\right) .{ }^{44}$

Therefore, as compared to the literature, the material M1-D obtained competitive $Q$ values while the material is not based on the commonly modification of mesoporous silica support with chelating ligand.

\section{Experimental}

Technical details

NMR analyses were performed on a Bruker 400 ultrashield VS spectrometer. Displacements are reported in ppm using the solvent $\left(\mathrm{CDCl}_{3}: 7.26 \mathrm{ppm}\right.$ for ${ }^{1} \mathrm{H} ; 77.16 \mathrm{ppm}$ for $\left.{ }^{13} \mathrm{C}\right)$ as an internal reference.

ESI-MS was performed on a Flexar SQ 300 MS instrument.

TGA analyses were performed on a Setaram Setsys Evolution 18 instrument under airflow $\left(20 \mathrm{~mL} \mathrm{~min}^{-1}\right)$ with a heating rate of $\left(5^{\circ} \mathrm{C} \mathrm{min}^{-1}\right)$. The coupled mass spectrometer was a Hiden analytical QGA instrument.

Solid-state FT-IR spectra were obtained using an ATR crystal on a Perkin-Elmer 100 spectrometer with a resolution of $4 \mathrm{~cm}^{-1}$.

Solid-state ${ }^{13} \mathrm{C} C P$ MAS NMR spectra were performed on a Bruker 400 ultrashield VS spectrometer with a $12 \mathrm{kHz}$ MAS spinning rate using Bruker MAS probes (4 mm rotors). The typical contact time was 2-3 ms, and the typical recycle delay was 5-30 s. The degrees of condensation were estimated from the

${ }^{29} \mathrm{Si}$ CPMAS NMR spectra from the percentages of the different $\mathrm{T}^{\mathrm{x}}$ units, which were obtained by deconvolution of the spectra using the Dmfit program. ${ }^{45}$

SAXS experiments were performed on a setup operating in transmission geometry. A Mo anode associated with a Fox2D multi-shell mirror (XENOCS) delivered a collimated beam of wavelength $0.71 \AA$. Two sets of scatterless slits46 delimitated the beam to a square section of side length of $0.8 \mathrm{~mm}$. A MAR345 imaging plate detector allowed simultaneous recording of scattering vectors q ranging from $0.25 \mathrm{~nm}^{-1}$ to $25 \mathrm{~nm}^{-1}$. Samples were placed in glass capillaries with a diameter of $2 \mathrm{~mm}$. Absolute intensities were obtained by measuring a calibration sample of high-density polyethylene (Goodfellow), for which the absolute scattering was already determined.

All SAXS profiles are plotted in log-log scale to highlight the dependency of the intensity versus a power law of the scattering vector $\mathrm{q}$.

Metal concentrations were measured by inductively coupled plasma/atomic emission spectroscopy (ICP/AES) using a SPECTRO ARCOS spectrometer. 


\section{Precursor synthesis}

All intermediate reactants and final products $\mathrm{P} 1$ and $\mathrm{P} 2$ were purified by distillation under a vacuum. ${ }^{1} \mathrm{H},{ }^{13} \mathrm{C} \mathrm{NMR}$, and mass spectrometry were used at each step to verify the structure and purity of the different products; all of the chemical characterizations were in agreement with the literature. ${ }^{47-49}$

Synthesis of P1. The organic precursor P1 was synthesized starting from 10-undecen-1-ol in four steps (Scheme $\mathrm{S1}, \mathrm{ESI}$ ) in anhydrous conditions through the mesylation of the alcohol, which allow for higher yields than the bromination described in the literature: ${ }^{47,48}$

As shown in Scheme S1 (ESI), 1 (34.058 g, 0.2 mol, 1 eq.) and NEt 3 (25.5 g, 0.252 mol, 1.26 eq.) were added to $700 \mathrm{Ml} \mathrm{CHCl}_{3}$. Over the course of $90 \mathrm{~min}, \mathrm{MsCl}\left(27.494 \mathrm{~g}, 0.24 \mathrm{~mol}, 1.2\right.$ eq.) dissolved in $100 \mathrm{~mL}$ of $\mathrm{CHCl}_{3}$ was added dropwise into the stirred solution at room temperature. The temperature was controlled by a water bath. Addition of $\mathrm{MsCl}$ produced $\mathrm{HCl}$, which was removed by frequent venting. After $20 \mathrm{~h}$, the solution turned slightly yellow. Half of the reaction mixture was washed with $450 \mathrm{~mL}$ water. The aqueous phase was extracted with $\mathrm{CHCl}_{3}$ $(2 \times 100 \mathrm{~mL})$. The same process was repeated for the second half. All the united aqueous phases were again extracted with $\mathrm{CHCl}_{3}(100 \mathrm{~mL})$. The organic phases were reduced to $200 \mathrm{~mL}$ and washed with brine $(100 \mathrm{~mL})$. $\mathrm{CHCl}_{3}$ was evaporated, and the residue was distilled at $80{ }^{\circ} \mathrm{C}$ and $0.5 \mathrm{mbar}$ to remove volatile impurities. The resulting dark oil was again distilled at $160{ }^{\circ} \mathrm{C}$ and $0.3 \mathrm{mbar}$ to afford product 2 as translucent brown oil (45.12 g, $0.18 \mathrm{~mol}, 91 \%)$ in the distillate. Under $\mathrm{N}_{2}$-atmosphere, Karstedt catalyst (2.1-2.4 wt\% Pt, $0.462 \mathrm{~g}, 0.02 \mathrm{mmol}$, $3 \times 10^{-4}$ eq.) was added to a stirred mixture of 2 (15 g, $60.05 \mathrm{mmol}, 1$ eq.) and triethoxysilane (22.99 g,

$139.94 \mathrm{mmol}, 2.33$ eq.) at room temperature. The temperature was kept constant using a water bath. After 20 $\mathrm{h}$, activated charcoal $(2 \mathrm{~g})$ was added, and the mixture was stirred at $40^{\circ} \mathrm{C}$ for $1 \mathrm{~h}$. The mixture was filtered, and the filtrate was distilled at $170{ }^{\circ} \mathrm{C}(0.3 \mathrm{mbar})$ to remove more volatile impurities. Product 3 was obtained as brown oil (21.87 g, $53.06 \mathrm{mmol}, 88 \%)$. Under $\mathrm{N}_{2}$-atmosphere, $\mathrm{NaN}_{3}$ (7.09, $109.14 \mathrm{mmol}, 3$ eq.) suspended in $\mathrm{CH}_{3} \mathrm{CN}(100 \mathrm{~mL})$ was heated to $85^{\circ} \mathrm{C} .3\left(15 \mathrm{~g}, 36.4 \mathrm{mmol}, 1\right.$ eq.) in $\mathrm{CH}_{3} \mathrm{CN}$ (50 mL) was added dropwise to the heated mixture. After $48 \mathrm{~h}$ the mixture was cooled to $0{ }^{\circ} \mathrm{C}$ filtered, washing the residue with cold $\mathrm{CH} 3 \mathrm{CN}(2 \times 20$ $\mathrm{mL}$ ). After evaporation of $\mathrm{CH}_{3} \mathrm{CN}$ more volatile compounds were removed by distillation at $110{ }^{\circ} \mathrm{C}(0.6 \mathrm{mbar})$ for $2 \mathrm{~h}$. The residue was distilled $200{ }^{\circ} \mathrm{C}(0.6 \mathrm{mbar})$ to afford the product 4 as clear, colourless oil $(11.94 \mathrm{~g}, 31.75$ $\mathrm{mmol}, 87 \%$ ) in the distillate.

Reduction of the azido group with palladium (10\% Pd/C, Sigma-Aldrich) in anhydrous ethanol under hydrogen atmosphere led to amino-undecyl-triethoxysilane P1. Under an Ar-atmosphere, anhydrous ethanol ( $500 \mathrm{~mL}$ ) was added to Palladium supported on carbon (Pd/C, $10 \mathrm{w} \%)(0.2 \mathrm{~g}, 0.19 \mathrm{mmol}, 0.01 \mathrm{eq}$.), and 4 balloons filled with $\mathrm{H}_{2}$ were bubbled through.

A solution of 4 ( $7.9 \mathrm{~g}, 21 \mathrm{mmol}, 1$ eq.) dissolved in anhydrous ethanol ( $250 \mathrm{~mL}$ ) was infused by bubbling through one balloon of $\mathrm{H}_{2}$. The solution containing 4 was then added dropwise under an $\mathrm{H}_{2}$ atmosphere over the course of $1 \mathrm{~h}$. After $2 \mathrm{~h}$ of stirring at room temperature, the solution was filtered over Celite, and the solvent of the filtrate was evaporated. The residue was dissolved in pentane, and the resulting solution containing a white precipitate was again filtered over Celite. The pentane was evaporated, and the product P1 was obtained as a slightly yellow liquid $(5.5 \mathrm{~g}, 16.4 \mathrm{mmol}, 78 \%)$ after fractionated distillation at $200{ }^{\circ} \mathrm{C}(0.7 \mathrm{mbar})$.

Synthesis of P2. The organic precursor P2 was synthesized in the three steps described in the literature. ${ }^{49}$ Bromoundecene (Alpha Aesar) was condensed with $\mathrm{N}$-hydroxy-phthalimide in a Williamson's type reaction. Then, a Gabriel's type reaction using hydrazine led to amino-oxy-undecene. After purification, the latter molecule was reacted with triethoxysilane using a Karstedt catalyst purchased from ABCR to obtain amino-oxyundecyltriethoxysilane.

\section{Materials synthesis}

Synthesis of M1. The procedure for preparing the initial material starting from amino-undecyl-triethoxysilane (P1) and containing a carbamate ammonium salt was adapted from the procedure described previously. ${ }^{27}$ Amino-undecyl-triethoxysilane ( $3 \mathrm{mmol}$ ) was introduced in a $50 \mathrm{~mL}$ flask under pure $\mathrm{CO}_{2}$ gas, resulting in a gel. After $30 \mathrm{~min}, 20 \mathrm{~mL}$ of pentane were poured in the flask and then hydrochloric acid solution was added $(81 \mathrm{~mL}$ at $\mathrm{pH}$ 1.5). The material was aged for 3 days at $30{ }^{\circ} \mathrm{C}$. The resulting material $\mathrm{M} 1$ was obtained after filtration followed by a washing step with ethanol and ether before drying under vacuum. 
Synthesis of M2. Samples were prepared as follows: $3 \mathrm{mmol}$ of oxy-undecyl-triethoxysilane (P2) were introduced into $20 \mathrm{Ml}$ of pentane, then $80 \mathrm{~mL}$ of hydrochloric acid solution at $\mathrm{pH}=1.5$ was added. The solution was stirred for ageing for three days before neutralized at $\mathrm{pH}=7$ with ammonia. The resulting material was washed with ethanol and ether. Then, the powders were dried under a vacuum for 1 hour.

\section{Post-grafting}

The opening ring of the different cyclic anhydrides by the amino functionalities of M1 was performed as follows: the M1 material was added to a solution of THF containing 1.1 equivalent of cyclic anhydride (succinic, glutaric or diglycolic) in regard to the amino function contained in M1. The resulting materials are respectively denoted as M1-S, M1-G, and M1-D.

The mixture was stirred for 12 hours at $70{ }^{\circ} \mathrm{C}$. After stirring for 12 hours at $70{ }^{\circ} \mathrm{C}$, the mixture was centrifuged at $4500 \mathrm{rpm}$ for $15 \mathrm{~min}$. Then, the resulting materials were rinsed with ethanol and ether. Finally, the powders were dried under a vacuum for 1 hour.

\section{Extraction test}

All adsorption experiments were conducted using batch contact methodology in which the powdered adsorbent was contacted with solutions containing the target species in a volume/mass ratio of approximately $400-500 \mathrm{~mL}$ $\mathrm{g}^{-1}$. The adsorbent material (20-25 mg) was added to $10 \mathrm{~mL}$ of a solution containing metal ions, and the mixture was stirred at $298 \mathrm{~K}$ for $24 \mathrm{~h}$. After centrifugation at $4500 \mathrm{rpm}$ for $15 \mathrm{~min}$, the concentration of metal ions in the filtrate was measured by inductively coupled plasma optical emission spectroscopy. The uptake of metal ions efficiency $E \%$ was calculated from the following equation, in which $C_{i}$ and $C_{f}$ are the initial and the final concentration of metal ions, respectively:

$E \%=\frac{C_{i}-C_{f}}{C_{i}} \times 100$

The cation uptake capacity $Q$ of the samples was calculated using eqn (7), in which $C_{i}$ is the initial concentration of the metal ion in solution, $C_{f}$ is the residual metal ion concentration, and $V / m$ is the solution volume to solidmass ratio ( $V=$ volume of the treated solution and $m=$ mass of the nanocomposite used):

$\mathrm{Q}=\left(\mathrm{C}_{\mathrm{i}}-\mathrm{C}_{\mathrm{f}}\right) \cdot \frac{\mathrm{V}}{\mathrm{m}}$

The separation factor $\left(\mathrm{SF}_{\mathrm{Ma} / \mathrm{Mb}}\right)$ or selectivity is given by the following:

$\mathrm{SF}=\frac{\mathrm{Q}_{\mathrm{Ma}}}{\mathrm{Q}_{\mathrm{Mb}}}$

$\mathrm{Q}_{\mathrm{Ma}}$ and $\mathrm{Q}_{\mathrm{Mb}}$ are the cation uptake capacity of the competitive ions $\mathrm{Ma}$ and $\mathrm{Mb}$, respectively.

\section{Conclusions}

We demonstrated the complete accessibility and availability of amines from carbamate interfaces between bilayers in regard to metal ions and the ring opening reaction of anhydrides.

Similar but shifted extraction behaviours of amino and oxyamino@silica materials suggest that their extraction properties are governed by the pKa of the amine moiety.

The ring opening reaction of anhydrides in the $\mathrm{M} 1$ material has been quantitatively performed, as indicated by complementary analyses such as TGA and elemental analyses, with three different anhydrides leading to succinamic, glutaramic, and diglycolamic acids.

The structure of the resulting materials is swelled by the grafted molecule hindrance but preserved.

As for the initial amino@silica material, the interactions at the amic bilayer interfaces do not prevent their accessibility regarding metal ions, allowing quantitative extraction and desextraction in nitric media.

Further work will be devoted to the selective extraction of REE with regards to Fe by first performing the extraction of the aqueous feed solution using M1-S or M1-G to remove the iron, and then performing the extraction of the REE thanks to the M1-D material. Indeed, the latter material, prepared by a simple and convenient approach, is a promising adsorbent in regards to its high extraction performance of REEs and their easy desorption.

\section{Conflicts of interest}

There are no conflicts to declare. 


\section{Acknowledgements}

The authors acknowledge C. Rey and V. Dubois for their technical support.

\section{Notes and references}

1 C. Sanchez, K. J. Shea and S. Kitagawa, Chem. Soc. Rev., 2011, 40, 471-472.

2 R. I. Nooney, M. Kalyanaraman, G. Kennedy and E. J. Maginn, Langmuir, 2001, 17, 528-533.

3 P. K. Jal, S. Patel and B. K. Mishra, Talanta, 2004, 62, 1005-1028.

4 G. Arrachart, I. Karatchevtseva, D. J. Cassidy, G. Triani, J. R. Bartlett and M. Wong Chi Man, J. Mater. Chem., 2008, 18, 3643-3649.

5 A. Charlot, S. E. Mourabit, F. Goettmann, G. Arrachart, R. Turgis and A. Grandjean, RSC Adv., 2014, 4, 64138-64141.

6 R. Turgis, G. Arrachart, C. Delchet, C. Rey, Y. Barre', S. Pellet-Rostaing, Y. Guari, J. Larionova and A. Grandjean, Chem. Mater., 2013, 25, 4447-4453.

7 A. Walcarius and L. Mercier, J. Mater. Chem., 2010, 20, 4478-4511.

8 H. Yoshitake, J. Mater. Chem., 2010, 20, 4537-4550.

9 F. Hoffmann, M. Cornelius, J. Morell and M. Fröba, Angew. Chem., Int. Ed., 2006, 45, 3216-3251.

10 W. J. Hunks and G. A. Ozin, J. Mater. Chem., 2005, 15, 3716-3724.

11 P. Van Der Voort, D. Esquivel, E. De Canck, F. Goethals, I. Van Driessche and F. J. Romero-Salguero, Chem. Soc. Rev., 2013, 42, 3913-3955.

12 M. H. Lim, C. F. Blanford and A. Stein, Chem. Mater., 1998, 10, 467-470.

13 M. H. Lim and A. Stein, Chem. Mater., 1999, 11, 3285-3295.

14 A. Walcarius and C. Delacôte, Chem. Mater., 2003, 15, 4181-4192.

15 E. Ruiz-Hitzky, S. Letaïef and V. Prévot, Adv. Mater., 2002, 14, 439-443.

16 R. Voss, A. Thomas, M. Antonietti and G. A. Ozin, J. Mater. Chem., 2005, 15, 4010-4014.

17 W. Otani, K. Kinbara, Q. Zhang, K. Ariga and T. Aida, Chem. - Eur. J., 2007, 13, 1731-1736.

18 T. Chujo, Y. Gonda, Y. Oumi, T. Sano and H. Yoshitake, J. Mater. Chem., 2007, 17, 1372-1380.

19 H. Yoshitake, H. Nakajima, Y. Oumi and T. Sano, J. Mater. Chem., 2010, 20, 2024-2032.

20 J. Alauzun, A. Mehdi, C. Reyé and R. J. P. Corriu, J. Am. Chem. Soc., 2005, 127, 11204-11205.

21 J. Alauzun, E. Besson, A. Mehdi, C. Reyé and R. J. P. Corriu, Chem. Mater., 2008, 20, 503-513.

22 R. Besnard, J. Cambedouzou, G. Arrachart, O. Diat and S. Pellet-Rostaing, Langmuir, 2013, 29, 10368-10375.

23 R. Besnard, G. Arrachart, J. Cambedouzou and S. Pellet-Rostaing, RSC Adv., 2015, 5, 57521-57531.

24 R. Besnard, G. Arrachart, J. Cambedouzou and S. Pellet-Rostaing, Langmuir, 2016, 32, 4624-4634.

25 R. Besnard, G. Arrachart, J. Cambedouzou and S. Pellet-Rostaing, J. Sol-Gel Sci. Technol., 2017, 81, $452-467$.

26 T. Yokoi, H. Yoshitake, T. Yamada, Y. Kubota and T. Tatsumi, J. Mater. Chem., 2006, 16, 1125-1135.

27 R. Besnard, J. Cambedouzou, G. Arrachart, X. F. Le Goff and S. Pellet-Rostaing, RSC Adv., 2015, 5, 77619-77628.

28 J. H. Clark and D. J. Macquarrie, Chem. Commun., 1998, 853-860.

29 Y. An, M. Chen, Q. Xue and W. Liu, J. Colloid Interface Sci., 2007, 311, 507-513.

30 G. T. Hermanson, Bioconjugate Techniques, Academic Press, New York, 2nd edn, 2008, pp. $169-212$.

31 K. A. Utting and D. J. Macquarrie, New J. Chem., 2000, 24, 591-595.

32 T. Ogata, H. Narita and M. Tanaka, Hydrometallurgy, 2015, 152, 178-182.

33 T. Ogata, H. Narita and M. Tanaka, Hydrometallurgy, 2016, 163, 156-160.

34 G. Careri, U. Buontempo, F. Galluzzi, A. C. Scott, E. Gratton and E. Shyamsunder, Phys. Rev. B: Condens. Matter Mater.

Phys., 1984, 30, 4689-4702.

35 G. Cerveau, R. J. P. Corriu, C. Lepeytre and P. Hubert Mutin, J. Mater. Chem., 1998, 8, $2707-2713$.

36 G. Arrachart, C. Carcel, P. Trens, J. J. E. Moreau and M. Wong Chi Man, Chem. - Eur. J., 2009, 15, 6279-6288.

37 A. Mehdi, J. Mater. Chem., 2010, 20, 9281-9286.

38 J.-C. Broudic, O. Conocar, J. J. E. Moreau, D. Meyer and M. Wong Chi Man, J. Mater. Chem., 1999, 9, $2283-2285$.

39 G. E. Fryxell, H. Wu, Y. Lin, W. J. Shaw, J. C. Birnbaum, J. C. Linehan, Z. Nie, K. Kemner and S. Kelly, J. Mater. Chem., 2004, 14, 3356-3363.

40 T. Ogata, H. Narita and M. Tanaka, Chem. Lett., 2014, 43, 1414-1416.

41 A. S. Suneesh, K. V. Syamala, K. A. Venkatesan, M. P. Antony and P. R. Vasudeva Rao, J. Colloid Interface Sci., 2015, 438, 55-60.

42 E. M. Soliman, Anal. Lett., 1997, 30, 1739-1751.

43 Y.M. Hu, E. Drouin, D. Lariviere, F. Kleitz and F. G. Fontaine, ACS Appl. Mater. Interfaces, 2017, 9, 38584-38593. 
44 X. Zheng, C. Wang, J. Dai, W. Shi and Y. Yan, J. Mater. Chem. A, 2015, 3, 10327-10335.

45 D. Massiot, F. Fayon, M. Capron, I. King, S. Le Calvé, B. Alonso, J.-O. Durand, B. Bujoli, Z. Gan and G. Hoatson, Magn. Reson. Chem., 2002, 40, 70-76.

46 Y. Li, R. Beck, T. Huang, M. C. Choi and M. Divinagracia, J. Appl. Crystallogr., 2008, 41, 1134-1139.

47 B. P. Pichon, M. Wong Chi Man, C. Bied and J. J. E. Moreau, J. Organomet. Chem., 2006, 691, 1126-1130.

48 S. Lambert, K. Y. Tran, G. Arrachart, F. Noville, C. Henrist, C. Bied, J. J. E. Moreau, M. Wong Chi Man and B. Heinrichs, Microporous Mesoporous Mater., 2008, 115, 609-617.

49 F. Martin, A. Diran, J.-O. Durand, M. Granier and R. Desmet, Tetrahedron Lett., 2005, 46, 7973-7975. 